\title{
A New Reagent for the tert-Butyloxycarbonylation of Amino Acids
}

The introduction of the tert-butyloxycarbonyl ( $\mathrm{BOC}-$ ) group for the protecting of amino group has been a major contribution to peptide syntheses.

Although tert-butyl $p$-nitrophenyl carbonate ${ }^{1)}$ and tert-butyl azidoformate ${ }^{2)}$ have been commonly used as tert-butyloxycarbonylating reagents, the tert-butyl $p$-nitrophenyl carbonate method usually gives poor yields of the resulting BOC-amino acids whereas the tert-butyl azidoformate method requires many steps for the preparation of the azidoformate.

In the present study, tert-butyl pentachlorophenyl carbonate (BOC-OPCP) was found to be a useful reagent for the same purpose.

BOC-OPCP could be readily prepared in good yield as a stable crystalline by the reaction of pentachlorophenyl chloroformate ${ }^{3)}$ with tert-butyl alcohol in a benzene solution in the presence of pyridine. Crystalline BOC-OPCP, m.p. 116 117 (80\% yield), was obtained from ethanol-benzene. Its structure is supported by the analytical and infrared data. Anal. Calcd. for $\mathrm{C}_{11} \mathrm{H}_{9} \mathrm{O}_{3} \mathrm{Cl}_{5}: \mathrm{C}, 36.05 ; \mathrm{H}, 2.48 ; \mathrm{Cl}, 48.58$. Found : C, 36.04; $\mathrm{H}$, $2.39 ; \mathrm{Cl}, 48.39$. IR $\nu_{\max }^{\mathrm{KBr}} \mathrm{cm}^{-1}: 1775(\mathrm{C}=\mathrm{O}), 1250\left(\mathrm{C}\left(\mathrm{CH}_{3}\right)_{3}\right)$.

TABLE I. Preparation of tert-Butyl-and tert-Amyl-oxycarbonyl Amino Acids by tert-Alkyl Pentachlorophenyl Carbonate Method

\begin{tabular}{|c|c|c|c|c|c|c|c|}
\hline \multirow{2}{*}{ Compound } & \multirow{2}{*}{$\begin{array}{c}\text { Yield } \\
(\%)\end{array}$} & \multicolumn{4}{|c|}{ m.p. $\left({ }^{\circ} \mathrm{C}\right)$} & \multicolumn{2}{|c|}{$[\alpha]_{\mathrm{D}}\left(\right.$ temp.,$\left.{ }^{\circ} \mathrm{C}\right)$} \\
\hline & & \multicolumn{2}{|c|}{ Found } & & lit. & Found & lit. \\
\hline \multicolumn{8}{|l|}{ BOC-deriv. of } \\
\hline Alanine & 61 & 73 & $\sim 74$ & 83 & $\sim 84^{1)}$ & $-24.5(23)$ & $-22.4(25)^{1)}$ \\
\hline$\beta$-Alanine & 71 & 76 & $\sim 78$ & 73 & $\sim 74^{6)}$ & & \\
\hline$\beta$-Benzylaspartate & 60 & \multicolumn{2}{|c|}{101} & \multicolumn{2}{|c|}{$101^{7)}$} & $-17.4(23)$ & $-19.5(22)^{7)}$ \\
\hline Isoleucine $^{a)}$ & 64 & 50 & $\sim 58$ & 49 & $\sim 57^{1)}$ & $+2.8(23)$ & $+3.0(25)^{1)}$ \\
\hline Leucine $^{b)}$ & 71 & 70 & $\sim 73$ & 67 & $\sim 72^{1)}$ & $-24.2(23)$ & $-24 \quad(25)^{1)}$ \\
\hline Methionine & 87 & \multicolumn{2}{|c|}{ Oil } & \multicolumn{2}{|r|}{$\mathrm{Oil}^{1)}$} & & \\
\hline Nitroarginine & 63 & 102 & $\sim 104$ & 98 & $\sim 102^{8)}$ & $-5.8(23)$ & $-5.9(28)^{8)}$ \\
\hline Phenylalanine $\cdot \mathrm{DCHA}^{c}$ ) & 85 & 210 & $\sim 212$ & 210 & $\sim 212^{9)}$ & $+29.2(23)$ & $\left.+28.9(25.5)^{9}\right)$ \\
\hline Proline & 73 & 135 & $\sim 137$ & 136 & $\sim 137^{1)}$ & $-59.1(23)$ & $-60.2(25)^{1)}$ \\
\hline Tryptophan & 73 & 140.5 & $5 \sim 141$ & 136. & $5 \sim 140.5^{1)}$ & $-19.6(23)$ & $-18.2(25)^{1)}$ \\
\hline Valine & 83 & & Oil & & $\mathrm{Oil}^{2)}$ & & \\
\hline \multicolumn{8}{|l|}{ AOC-deriv. of } \\
\hline Glycine & 67 & 80 & $\sim 32$ & \multicolumn{2}{|c|}{$82.5 \sim 84^{5)}$} & & \\
\hline Methionine & 89 & & Oil & & $\mathrm{Oil}^{5)}$ & & \\
\hline Phenylalanine $\left.\cdot \mathrm{DCHA}^{q}\right)$ & 90 & 204 & $\sim 206.5$ & 198 & $\left.\sim 199^{5}\right)$ & $+35.2(23)$ & $+27.4(21)^{5)}$ \\
\hline Tryptophan & 75 & 132 & $\sim 133$ & 121 & $\left.\sim 123^{5}\right)$ & $+7.2(23)$ & $+7.1(21)^{5)}$ \\
\hline
\end{tabular}

a) Hemihydrate.

b) Hydrate.

c) Dicyclohexylammonium salt.

1) G. W. Anderson, A. C. McGregor : J. Am. Chem. Soc., 79, 6180 (1957).

2) R. Schwyzer, P. Sieber, H. Kappeler: Helv. Chim. Acta, 42, 2622 (1959).

3) Pentachlorophenyl chloroformate was easily prepared in a stable crystalline from by allowing pentachlorophenol (commercial, 90\% pure) to react with excess phosgen in a benzene-tetrahydrofuran solution in the presence of triethylamine, m.p. $58^{\circ}$.

4) Amino acid (0.1 mole) was dissolved in cooled $4 N$-sodium hydroxide ( $25 \mathrm{ml}$.$) .$

5) S. Sakakibara, M. Shin, M. Fujino, Y. Shimonishi, S. Inoue, N. Inukai : Bull. Chem. Soc. Japan, 38, $1522(1965)$

6) P. H. Bently, H. Gregory, A. H. Laird, J. S. Morley : J. Org. Chem., 29, 6130 (1964).

7) Ed. Sandrin, R. A. Boissonnas : Helv. Chem. Acta, 178, 1642 (1963),

8) K. Inouye : Bull. Chem. Soc. Japan, 38, 1148 (1965).

9) H. Otsuka, K. Inouye : Bull. Chem. Soc. Japan, 37, 1465 (1964). 
The aminolysis of the carbonate ( $40 \mathrm{~g} ., 0.12 \mathrm{~mol}$.) with sodium salt ${ }^{4}$ ) of amino acid $(0.10 \mathrm{~mol}$.) was carried out in a mixture of dimethylformamide $(100 \mathrm{ml}$.$) and chloroform$ $(50 \mathrm{ml}$.) in the presence of triethylamine $(14 \mathrm{ml}$.) at room temperature for 24 hours. Chloroform $(200 \mathrm{ml}$.) was added to the reaction mixture and then the sodium salt of the resulting $\mathrm{BOC}$-amino acid was extracted with water. The aqueous extract was washed with ethyl acetate and then acidified with $N$-hydrochloric acid $(200 \mathrm{ml}$.) under cooling and immediately extracted with ethyl acetate. From the ethyl acetate solution, BOC-amino acid was isolated by a usual manner. The yields and physical constants of the BOCamino acids so synthesized were listed in Table $I$.

For the racemization test, BOC-isoleucine (listed in Table I) wes deacylated with trifluoroacetic acid and then subjected to the amino acid analyzer (Beckman 120B): Isoleucine, $101 \pm 5 \%$. Alloisoleucine, not detected.

Therefore the use of this reagent for usual BOC-amino acid synthesis must be safe against their racemization.

Incidentally, tert-amyloxycarbonyl (AOC-) amino acids ${ }^{5}$ ) were prepared by the same procedures as described above, employing tert-amyl pentachlorophenyl carbonate (m.p. $88 \sim 90^{\circ}, 83 \%$ yield) which was obtained by reacting pentachlorophenyl chloroformate with tert-amyl alcohol. The yields and physical constants of the AOC-amino acids thus obtained were also listed in Table I.

The authors are grateful to Drs. S. Tatsuoka, Y. Abe, J. Ueyanagi and Y. Sanno of this Division for their encouragement and useful discussion throughout this work. Thanks are also due to Dr. Asahi and his associates for optical rotations.

Chemical Research Laboratories Research and Development Division Takeda Chemical Ind., Ltd. Juso, Higashiyodogawa-ku, Osaka

\author{
Masahiko Fujino （藤野政产） \\ Chitoshi Hatanaka（烟中千年）
}

Received August 23, 1967 